\title{
Sex determination in annual fishes: Searching for the master sex-determining gene in Austrolebias charrua (Cyprinodontiformes, Rivulidae)
}

\author{
María José Arezo ${ }^{1}$, Nicolás Papa ${ }^{1}$, Verónica Guttierrez ${ }^{2}$, Graciela García ${ }^{2}$ and Nibia Berois ${ }^{1}$ \\ ${ }^{1}$ Sección Biología Celular, Facultad de Ciencias, Universidad de la República, Montevideo, Uruguay. \\ ${ }^{2}$ Sección Genética Evolutiva, Facultad de Ciencias, Universidad de la República, Montevideo, Uruguay.
}

\begin{abstract}
Evolution of sex determination and differentiation in fishes involves a broad range of sex strategies (hermaphroditism, gonochorism, unisexuality, environmental and genetic sex determination). Annual fishes inhabit temporary ponds that dry out during the dry season when adults die. The embryos exhibit an atypical developmental pattern and remain buried in the bottom mud until the next rainy season. To elucidate genomic factors involved in the sex determination in annual fish, we explored the presence of a candidate sex-specific gene related to the cascade network in Austrolebias charrua. All phylogenetic analyses showed a high posterior probability of occurrence for a clade integrated by nuclear sequences (aprox. 900 bp) from both adults (male and female), with partial cDNA fragments of $A$. charrua from juveniles (male) and the $d s x D$. melanogastergene. The expressed fragment was detected from blastula to adulthood stages showing a sexually dimorphic expression pattern. The isolated cDNA sequence is clearly related to $d s x D$. melanogaster gene and might be located near the top of the sex determination cascade in this species.
\end{abstract}

Keywords: annual fish, development, sex determination, doublesex gene related sequence.

Received: July 26, 2013; Accepted: January 9, 2014.

\section{Introduction}

In vertebrates different master genes acting on sex determination have been identified. In most mammals, Sry (testis-determining gene) located in the $\mathrm{Y}$ chromosome is the transcription factor that triggers the testis determining cascade. The first non-mammalian master gene was discovered in fish (Oryzias latipes dmy). In birds, Dmrt1 (doublesex-mab-3 related transcription factor 1) located in the $\mathrm{Z}$ chromosome plays this role while in Xenopus laevis, $D M-W$ a truncated copy of Dmrt1 found in the W chromosome, determines ovary fate in this species (Marín and Baker, 1998; Graves and Peichel, 2010).

Recently, four strong master sex determining candidate genes were identified in fish: amhy in Odontesthes hatchei, gsdf in Oryzias luzonensis, amhr2 in Takifugu rubripes and $s d Y$ in Oncorhynchus mykiss. Three of the four sex determining candidate genes (amhy, gsdf and $a m h r 2$ ) code for growth factors and one of their receptors demonstrating that novel actors, other than transcription factors, can be recruited at the top of the sex determination cascade (reviewed by Kikuchi and Hamaguchi, 2013).

Downstream genes involved in sex differentiation regulatory cascades are conserved in vertebrates and inver-

Send correspondence to María José Arezo. Sección Biología Celular, Facultad de Ciencias, Universidad de la República, Igua 4225, 11400, Montevideo, Uruguay. E- mail: mjarezo@ gmail.com. tebrates (Smith et al., 1999). Among these genes, a DM gene family, Dmrt (doublesex-mab-3 related transcription factor) is expressed in association with the development of sex-specific organs in all animals studied to date (Kopp, 2012).

The first identified family member: Dmrt1, exhibits an expression pattern mainly involved in postnatal (or post hatching) male gonad development (Hodgkin, 2002; Yamaguchi et al., 2006). In some fish species, its expression pattern is restricted to testes (e.g Oryzias latipes, Kobayashi et al., 2004) while in others it is expressed in both gonads (e.g. Odontesthes bonariensis, Fernandino et al., 2008). In hermaphrodite fish species Dmrt1 expression is related to male differentiation phases (Herpin and Schartl, 2011). The interest in this gene was greater after the discovery that Dmrt1 paralogs have moved up in the regulatory hierarchy from downstream position in gonad differentiation to the top of sex determination cascade in at least three distantly related organisms (O. latipes, Xenopus laevis and chicken Kopp, 2012). In O. latipes the male sex specific Dmrt1 copy, Dmrt1b(Y) (Nanda et al., 2002) or dmy (Matsuda et al., 2002), is located in the Y chromosome with a function equivalent to mammalian Sry (male master sex determining gene). The $\operatorname{Dmrt} 1 b(Y)$ gene is expressed in male embryos before gonadal differentiation (early development: neurula stage, Nanda et al., 2002). It is involved in the specification and maintenance of Sertoli cells fate and 
inhibits male germ cell division at the beginning of gonadal differentiation (Herpin et al., 2007). The autosomal paralogue Dmrt1a begins its expression between 20-30 days post hatching during testicular differentiation (Kobayashi et al., 2004). In adult testes both paralogues are expressed but Dmrtla predominates (Hornung et al., 2007). It has been demonstrated that an insertion of a transposable element is responsible for the regulation of Dmrt $1 b Y$ expression and also contributed to the establishment of this new regulatory hierarchy (Herpin et al., 2010).

Fishes represent the most basal and diverse vertebrate group enclosing next to 28,000 species (Nelson, 2006). This diversity includes different mechanisms involved in sex determination (genetic and environmental) and sex differentiation (unisexuality, hermaphroditism: synchronic or sequential and gonochorism: undifferentiated or differentiated) (Devlin and Nagahama, 2002). Sex determination systems differ in closely related fish species, even in populations of the same species (Conover and Kynard, 1981; Devlin and Nagahama, 2002). The evolutionary basis of this variability could be explained by ancient genomic duplication events that caused extra gene copies capable to acquire new functions and probably additional plasticity in the sex determination gene networks. The ability to modify sex determination control could be selected in response to environmental disturbances affecting sexual proportions (Mank et al., 2006). This fact could be critical as an adaptation to environmental shifts (e.g. temperature increments) that result in one sex proportion bias affecting population survival. In this context, the possibility to modify sex determination mechanisms could restore sex ratio balance according to the specific habitat condition in threatened species (Volff et al., 2007).

Annual fishes (Cyprinodontiformes; Aplocheiloidei) constitute a freshwater teleosts group with a short lifespan exposed to an extremely variable environment. They inhabit temporary ponds in South America and Africa that dry out during dry season leading to juvenile and adult death. The species survival depends on desiccationresistant embryos that remain hidden in the bottom mud until the next rainy season when they hatch (Myers, 1952; Wourms, 1967, Berois et al., 2012). In particular, Austrolebias charrua (Costa and Cheffe, 2001) is an annual fish species distributed from southern Brazil (Patos-Merín lagoon) to eastern Uruguay (Rocha Department). Chromosomal studies and analyses at DNA level demonstrated high genetic variations (García, 2006) and the existence of ancestral polymorphisms in certain $A$. charrua populations (García et al., 2009). Aspects related to reproductive diversity are essential to understand the evolution of these mechanisms as well as management of species that are considered potential environmental pollution biomonitors (Devlin and Nagahama, 2002).

Sex differentiation, determination of sexual strategy, and gametogenesis of this species were previously estab- lished (Arezo et al., 2007). There is no evidence about the mechanism of sex determination and no genetic sex markers have been identified so far. Moreover, until now there are no complete genome sequences available. Therefore, the aim of the present work is to focus on the identification of a key gene involved in A. charrua sex determination. As a first step we explored the presence of a candidate master sex-specific gene and its expression during ontogenesis.

\section{Materials and Methods}

\section{Sample collection, genomic DNA extraction, amplification, cloning and sequencing}

A total of 12 males and 18 females of $A$. charrua were collected from the same temporal ponds (Rocha Department, Uruguay, GPS: $33^{\circ} 54^{\prime} 09^{\prime \prime} \mathrm{S} / 53^{\circ} 40^{\prime} 38^{\prime \prime} \mathrm{W}$ ) and euthanized by anesthesia (1\%o 2-phenoxy-ethanol, Sigma) according to a protocol approved by the animal experimentation committee from the Universidad de la República, CHEA (Comisión Honoraria de Experimentación Animal; protocol code 13-02-08). Genomic DNA was isolated from ethanol-fixed liver tissue using sodium chloride protein precipitation, followed by ethanol precipitation (modified from Medrano et al., 1990). The DNA quality was determined in a $0.5 \%$ GelRed (BIOTIUM) stained $1 \%$ agarose gel using 1XTAE (Tris-Acetate-EDTA). Amplification of a candidate sex-specific gene was performed by the polymerase chain reaction (PCR) with the specific primers DMTYh (5' TCTGCTGAG CTCCCCGGG 3') and DMTYi (5' GCCTCGCAGCTTCTCA 3'), designed to isolate the male specific sex determining gene in $O$. latipes (Nanda et al., 2002). The PCR was carried out in a $15 \mu \mathrm{L}$ total volume using $9.9 \mu \mathrm{L}$ of $\mathrm{H}_{2} \mathrm{O}$ (Amresco), $1.5 \mu \mathrm{L}$ of $10 \mathrm{X}$ buffer, $0.6 \mu \mathrm{L}$ of $\mathrm{MgCl}_{2}(50 \mathrm{mM}), 0.3 \mu \mathrm{L}$ of dNTPs $(10 \mathrm{mM}), 0.5 \mu \mathrm{L}$ of each primer $(10 \mu \mathrm{M}), 0.2 \mu \mathrm{L}$ of $\mathrm{Taq}$ DNA polymerase $(5 \mathrm{U} / \mu \mathrm{L})$ (Invitrogen) and $1.5 \mu \mathrm{L}$ of DNA, under the following conditions: $94{ }^{\circ} \mathrm{C}$ for $5 \mathrm{~min}, 35$ cycles of $30 \mathrm{~s}$ at $94{ }^{\circ} \mathrm{C}, 30 \mathrm{~s}$ at $55^{\circ} \mathrm{C} ; 1 \mathrm{~min}$ at $72^{\circ} \mathrm{C}$, and a final extension step of $7 \mathrm{~min}$ at $72^{\circ} \mathrm{C}$. PCR products were visualized in $0.5 \%$ GelRed (BIOTIUM) stained agarose gels using 1XTAE (Tris-Acetate-EDTA).

Fragments of different length amplified in each individual were eluted with the GFX PCR DNA and Gel Band Purification kit (GE Healthcare Life Sciences) and cloned with the GeneJet 1.2 PCR cloning kit according to manufacturer's instructions (Fermentas). Recombinant plasmids were obtained by DNA minipreparations of individual clones by alkaline lysis (Sambrook et al., 1989). Sequencing reactions were performed on each template using the primers supplied in the cloning kit (pJET1.2 forward and pJET1.2 Reverse) in a Perkin-Elmer ABI Prism 377 Automated Sequencer (MACROGEN, Seoul, Korea). Nucleotide sequences were compared against the National Center for Biotechnology Information (NCBI) protein da- 
tabase using the BLAST program on the Basic Local Alignment Search Tool (BLAST) network service (Altschul et al., 1990).

\section{Total RNA extraction, amplification, cloning and sequencing}

Embryos were obtained, cultured and classified in: $1-128$ cells $(n=8)$, early blastula $(n=7)$, dispersion phase (annual fish late blastula) $(\mathrm{n}=7)$, reaggregation (annual fish gastrula) $(\mathrm{n}=10), 0-10$ somites $(\mathrm{n}=8), 10-20$ somites $(\mathrm{n}=11), 20-30$ somites $(\mathrm{n}=11), 3$ weeks post-fertilization $(\mathrm{n}=8)$, one month post-fertilization $(\mathrm{n}=10)$ and prehatching embryos $(n=10)$ as described by Arezo et al. $(2005,2007)$. Male and female juveniles $(n=6)$ and adult fishes $(n=6)$ were euthanized as described above. Total RNA was extracted with Trizol Reagent (Invitrogen) from different embryo stages (Table 1). RNA from juveniles and adult gonads were treated with DNase I (Invitrogen). Reverse transcription was carried out using $10 \mathrm{ng}$ of total RNA, $1 \mu \mathrm{L}$ oligo $(\mathrm{dT})_{20} 50 \mu \mathrm{M}$ (Invitrogen) and Superscript III Reverse Transcriptase (Invitrogen). To evaluate cDNA synthesis and absence of genomic DNA contamination, a PCR with $\beta$-actin primers from Danio rerio (Barrallo et al., 1999) was run using the same protocol described above. Amplification with DMTYh and DMTYi (Nanda et al., 2002) were also performed using the cDNA samples and the same PCR protocol already described except for the annealing temperature $\left(58^{\circ} \mathrm{C}\right)$. The obtained products were re-amplified modifying only the annealing temperature to $59{ }^{\circ} \mathrm{C}$. All PCR products were separated in $1 \%$ agarose gels (1XTAE buffer) and visualized with $0.5 \%$ GelRed (BIOTIUM).

Table 1 - Samples used for RNA extraction

\begin{tabular}{lc}
\hline Samples & $\mathrm{n}$ \\
\hline Embryo stages & 8 \\
1 -128 cells & 7 \\
early blastula & 7 \\
dispersed phase (annual fish late blastula) & 10 \\
reaggregation (annual fish gastrulation) & 8 \\
$0-10$ somites & 11 \\
$10-20$ somites & 11 \\
20 -30 somites & 8 \\
3 weeks post fertilization & 10 \\
4 weeks post fertilization & 10 \\
pre-hatching (about 38 days post-hatching) & 3 \\
Juveniles & 3 \\
males & 3 \\
female & 3 \\
Adult tissues (form different individuals) & \\
testes & 3 \\
ovaries & 3 \\
\hline
\end{tabular}

Fragments were eluted, cloned, sequenced and compared against the NCBI database as described above. The obtained RNA sequence was analyzed online at the RNAfold WebServer (Gruber et al., 2008; Lorenz et al., 2011). Default parameters at $20^{\circ} \mathrm{C}$ were selected.

\section{Phylogenetic analyses}

In order to resolve the phylogenetic relationships, an alignment with $A$. charrua isolated genomic fragments as described above and the Dmrt gene family sequences retrieved from GenBank (Table 2) was conducted using ClustalW (Thompson et al., 1997) implemented in MEGA4 (Tamura et al., 2007). Three data set were generated to develop phylogenetic analyses: a) one including four $A$. charrua isolated genomic fragments (two for male and two for female) vs. Dmrt gene family sequences from different fish groups (Table 2); b) we also carried out an analysis to reveal relationships between the expressed $A$. charrua partial cDNA fragment and Dmrt1 mRNAs retrieved from GenBank (Table 3); c) a reduced data set including four $A$. charrua isolated genomic fragments, the expressed A. charrua partial cDNA fragment and the $d s x D$. melanogaster sequence.

We used a non-model based method (MP, maximum-parsimony) in PAUP* 4.0b10 (Swofford, 2002). An

Table 2 - Dmrt gene family obtained from GenBank and fragments isolated from the Austrolebias charrua genome.

\begin{tabular}{|c|c|c|}
\hline Sequence & Organism & Accession number \\
\hline Dmrt1bY & Oryzias latipes & $A Y 129241.1$ \\
\hline$d m y$ & Oryzias curvinotus & $A B 091695.1$ \\
\hline Dmrt1 & Odontesthes hatcheri & EU864152.1 \\
\hline Dmrtla & Oryzias latipes & $A Y 524417.1$ \\
\hline Dmrt1 & Monopterus albus & $A F 421347.1$ \\
\hline Dmrt2 & Xiphophorus maculatus & $A F 350428.1$ \\
\hline Dmrt $2 a$ & Danio rerio & NM_130952.1 \\
\hline Dmrt2 & Takifugu rubripes & NM_001037946.1 \\
\hline Dmrt3a & Danio rerio & NM_001005779.2 \\
\hline Dmrt3 & Takifugu rubripes & NM_001037945.1 \\
\hline Dmrt3 & Tetraodon nigroviridis & $A J 251455.1$ \\
\hline Dmrt4 & Xiphophorus maculatus & $A F 350427.1$ \\
\hline Dmrt4 & Takifugu rubripes & NM_001037948.1 \\
\hline Dmrt4 & Tetraodon nigroviridis & $A J 251456.1$ \\
\hline Dmrt5 & Danio rerio & AY618549.1 \\
\hline Dmrt5 & Takifugu rubripes & NM_001037950.1 \\
\hline Dmrt5 & Xiphophorus maculatus & $D Q 335470.1$ \\
\hline Dmrt5 & Oryzias latipes & AB083691.1. \\
\hline$M N 1 A$ & Austrolebias charrua male & $J X 494415$ \\
\hline$M N 1 B$ & Austrolebias charrua male & $J X 494416$ \\
\hline$H N 2 A$ & Austrolebias charrua female & $J X 494417$ \\
\hline$H N 2 B$ & Austrolebias charrua female & $J X 494418$ \\
\hline
\end{tabular}


Table 3 - Dmrt1 and doublesex gene sequences obtained from GenBank and the expressed partial cDNA sequence isolated from Austrolebias charrua.

\begin{tabular}{|c|c|c|}
\hline Sequence & Organism & Accession number \\
\hline Dmrt1bY & Oryzias latipes & AY129241.1 \\
\hline dmy al & Oryzias latipes & $A Y 448017.2$ \\
\hline dmy a2 & Oryzias latipes & AY448018.2 \\
\hline Dmrt1a & Oryzias latipes & AY524417.1 \\
\hline Dmrtlc & Oryzias latipes & AY524419.1 \\
\hline Dmrtld & Oryzias latipes & AY524420.1 \\
\hline$d m y$ & Oryzias curvinotus & $A B 091695.1$ \\
\hline Dmrt1 & Oryzias curvinotus & AY157713.1 \\
\hline Dmrt1 & Oryzias marmoratus & AY521023.1 \\
\hline Dmrt1 & Oryzias celebensis & AY239587.1 \\
\hline Dmrt1 & Oryzias luzonensis & AY521021.1 \\
\hline Dmrt1 & Oryzias mekongensis & AY521020.1 \\
\hline Dmrt1 & Odontesthes bonariensis & AY319416.3 \\
\hline Dmrt1 & Kryptolebias marmoratus & DQ683742.1 \\
\hline Dmrtla & Odontesthes hatcheri & EU864152.1 \\
\hline Dmrt1b & Odontesthes hatcheri & EU864153.1 \\
\hline Dmrtlc & Odontesthes hatcheri & EU864154.1 \\
\hline Dmrt1 & Poecilia reticulata & HM046940.1 \\
\hline Dmrt1 & Xiphophorus maculatus & AF529187.1 \\
\hline Dmrt $1 b$ & Clarias gariepinus & FJ596555 \\
\hline Dmrtlc & Clarias gariepinus & FJ596556.1 \\
\hline Dmrt1 & Monopterus albus & $A F 421347$ \\
\hline Dmrt1 & Mus musculus & NM_O15826 \\
\hline$d s x$ & Drosophila doublesex & NM_079548 \\
\hline partial $c D N A$ & Austrolebias charrua & $J X 494419$ \\
\hline
\end{tabular}

equally weighted MP analysis was performed using heuristic search (MULPARS option, stepwise addition, treebisection-reconnection [TBR] branch swapping, 100 replicates). A strict consensus among rival trees was computed to reconcile equally parsimonious topologies. The degree of confidence assigned to nodes in the trees was assessed by bootstrapping with 500 replicates.

We also used two model-based approaches, i.e., maximum-likelihood (ML) and Bayesian inference (BI) implemented in BEAST v.1.5.4 (Drummond and Rambaut, 2007). For the ML and Bayesian analyses, the best-fitted nucleotide substitution models for the data set were determined in Modeltest v.3.7 (Posada and Crandall, 1998) based on the Akaike Information Criterion (Akaike, 1974), which simultaneously compares multiple nested or non-nested models.

For data set a) the best fit out of the 56 models was obtained with the general time-reversible model $(\mathrm{GTR}+\mathrm{G}$, Rodriguez et al., 1990), which includes six different nucleotide substitution types and variable substitution rates among sites drawn from a gamma distribution (G). The gamma distribution shape parameter in the data set was 0.7311 . For data set b) the best fitted model selected was $\mathrm{K} 81 \mathrm{uf}+\mathrm{G}$ model (K81+G: Kimura 3-parameter plus Gamma, Kimura 1981) with a gamma distribution shape parameter of 0.6519 . In dataset c), HKY85 (Hasegawa et al. 1985) resulted in the best fitted model of molecular evolution.

For data set a) the likelihood scores estimated for the selected model GTR $+\mathrm{G}$ was used as the prior settings for the ML analysis $(-\ln \mathrm{L}=32940.4721)$. A heuristic ML search (again with 100 replicates of stepwise addition and TBR branch swapping) implemented in PAUP* 4.0b10 (Swofford, 2002) was used. The robustness of the nodes was determined after 500 bootstrapping replicates as implemented in PhyML 3.0, according to the algorithm developed by Guindon et al. (2010). In this case, the NNI (a fast nearest neighbour edge interchange search) swapping algorithm option was implemented. For data set b) the likelihood scores estimated for the selected model $\mathrm{K} 81+\mathrm{G}$ were used as the prior settings for the ML analysis $(-\ln \mathrm{L}=$ -15985.54790). Finally, for the c) data set the likelihood scores estimated for the selected model HKY 85 were used as the prior settings for the $\mathrm{ML}$ analysis (- $\ln \mathrm{L}=-723.286$ ). All trees were rooted by means of an outgroup criterion using more distantly related sequences in each data set.

Bayesian posterior probabilities of the trees were calculated using the BEAST v.1.5.4 program (Drummond and Rambaut, 2007). BEAST performs Bayesian statistical inferences of parameters, such as divergence times, using MCMC as a framework. Input files were generated using Beauti v.1.5.4 (Drummond and Rambaut, 2007), assuming uncorrelated log-normal trees and a constant population size as prior information. This prior tree is the most suitable for trees describing the relationships between individuals in the same population/species (Drummond and Rambaut, 2007). The nucleotide substitution model and its parameter values were selected based on the aforementioned Modeltest v.3.7 (Posada and Crandall, 1998) results. We carried out two independent runs of 10 million generations. Trees and parameters were sampled every 1,000 iterations, with a burn-in of $10 \%$. Results for each run were visualized using the Tracer v.1.5 program (Rambaut and Drummond, 2009 ) to ensure stationarity and convergence. Each analysis was repeated many times to optimize the operators of the parameters until no suggestion message appeared in the $\log$ file. Posterior probabilities and the maximum credibility tree were calculated using the TreeAnnotator v.1.5.4 program (Drummond and Rambaut, 2007).

\section{Results}

The PCR amplifications employing the Dmrt1bY specific oligonucleotides (Nanda et al., 2002) detected two fragments of 1000 and $900 \mathrm{bp}$ in the $A$. charrua genome. They were cloned, sequenced and named M N1A and M N1B in male, and H N2A and H N2B in female respectively (Figure 1). The alignment of these sequences and highly related ones retrieved from GenBank (Table 2) revealed the 


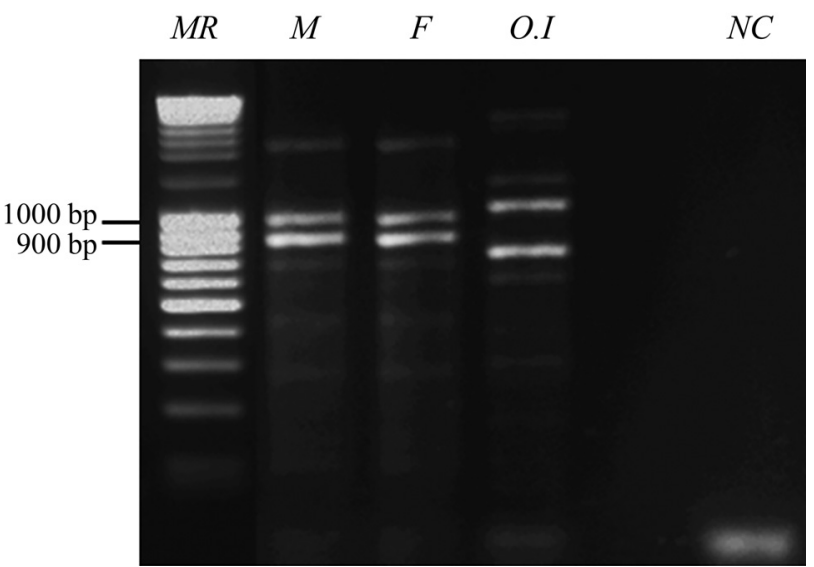

Figure 1 - Amplification products of Austrolebias charrua partial genome sequences in adult individuals. MR: Mass Ruler DNA ladder (Fermentas), M: A. charrua male, F: A. charrua female, O.l: O. latipes male (positive control), NC: negative control.

existence of 1084 variable sites and 1054 of parsimony informative sites. The average of the $\mathrm{Ts} / \mathrm{Tv}$ ratio calculated from all pairwise comparisons of samples was $\mathrm{R}=1227 \mathrm{in}$ dicating a low saturation level in the data set.

Phylogenetic analysis based on ML and BI phylogenetic tree reconstruction (Figure 2) showed a topology with three main supported clades integrated by: 1) autosomic Dmrtl sequences from $O$. latipes, $O$. hatcheri and Monopterus albus, Dmrt1bY from O. latipes, dmy from $O$. curvinotus and the isolated genomic sequences from $A$. charrua (70\% bootstrap support); 2) Dmrt2 sequences from Danio rerio, Xiphophorus maculatus and Takifugu rubripes (100\% boostrap support) and 3) Dmrt3 sequences from $D$. rerio and T. rubripes; Dmrt4 sequences from $X$. maculatus and T. rubripes genes and Dmrt5 sequences from $O$. latipes, $X$. maculatus, $D$. rerio and T. rubripes (63\% boostrap support). Tetraodon nigroviridis Dmrt3 and Dmrt4 resulted in most divergent sequences of this data set which collapsed in a basal polytomy with the aforementioned clades.

The RT-PCR amplifications with the same oligonucleotides (Nanda et al., 2002) revealed an expressed $205 \mathrm{bp}$ cDNA fragment in embryo stages from dispersed phase (late blastula) to pre-hatching embryos. Later on (juveniles and adults stages), the fragment was only detected in male individuals (Figure 3). This sequence showed 8\% of identity (e-value $=0.67$ ) with Dmrtl bY from $O$. latipes strain HNI (accession number AY129241.1) and dmy (accession number NM001104680.1). The BLAST search was restricted to Oryzias database. The corresponding translated fragment sequence included one stop codon. Remarkably there is an absence of a conserved DM domain in the partial cDNA fragment (205 bp) isolated in A. charrua male.

All phylogenetic analyses (MP, ML and $\mathrm{BI}$ ) of the isolated partial cDNA sequence with Dmrt1 mRNA sequences from different fish species Mus musculus Dmrt1 as

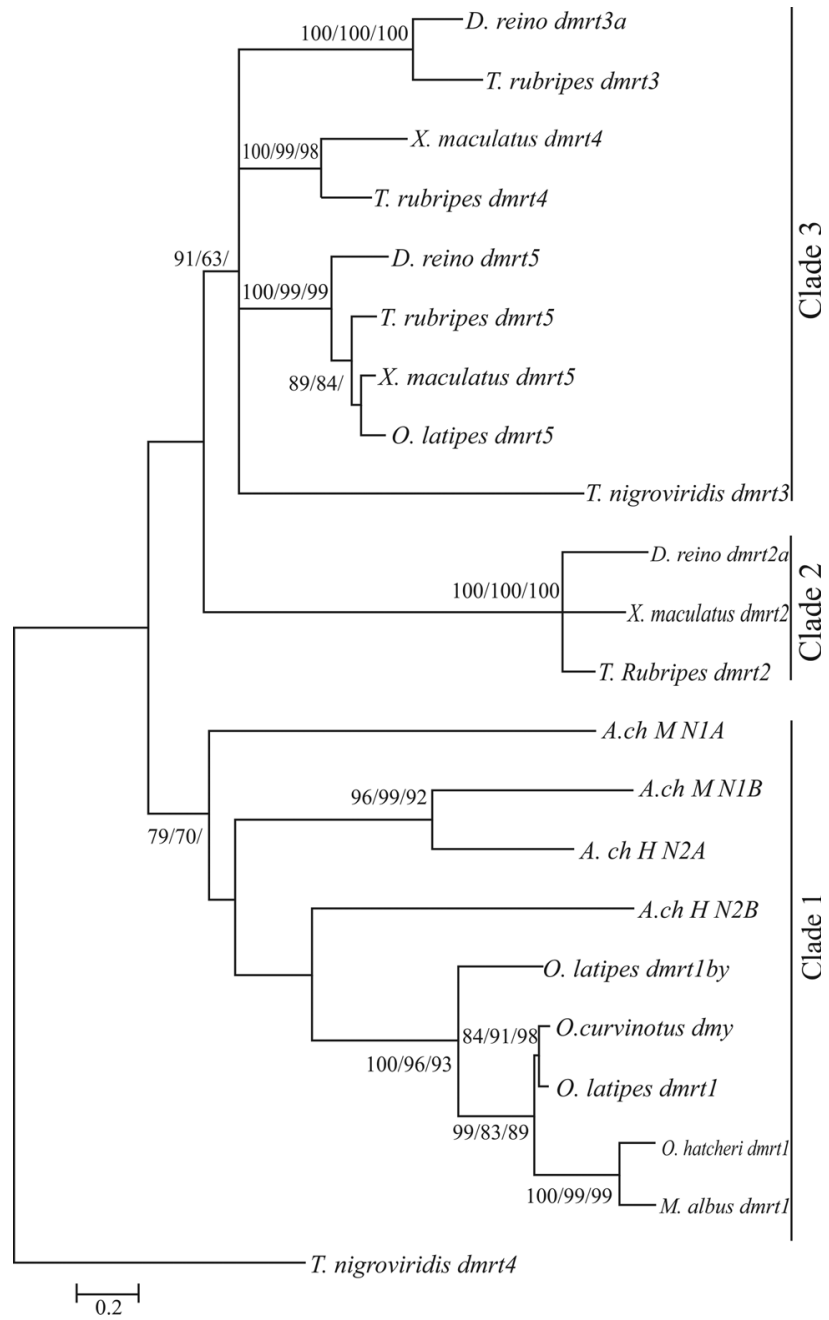

Figure 2 - Maximum Likelihood analyses [under general time-reversible model with gamma correction $(\mathrm{GTR}+\mathrm{G})]$, based on partial genome sequences isolated from Austrolebias charrua and Dmrt gene family sequences retrieved from GenBank (Table 2). Numbers above the branches (left to right) correspond to the Bayesian posterior probability for clades obtained using BEAST $1.5 .4 \mathrm{v}$, followed by ML and MP boostrap support $(>60 \%)$ respectively, recovered in 1000 replicates. M N1A, M N1B, H N2A and H N2B: Austrolebias charrua genomic fragments.

well as $D$. melanogaster $d s x$ gene were carried out (Figure 4). The tree topology shows two main clades (64\% bootstrap support). The major one is subdivided into four subclades embracing: 1) Dmrt1 mRNAs from some Oryzias species (O. latipes, O. luzonensis, O. curvinotus, $O$. mekognensis, $O$. marmoratus and $O$. celebensis), Dmrt $1 b Y$ (male specific duplication) and alternative splicing Dmrt1 variants from O. latipes and O. curvinotus $(99 \%$ bootstrap support); 2) Dmrt1 mRNAs from $O$. bonariensis and $O$. hatcheri (97\% bootstrap support); 3) Dmrt1 mRNAs from Poecilia reticulata and X. maculatus (98\% bootstrap support) and 4) $d s x$ mRNA from Drosophila, two alternative splicing versions of Dmrt1 from O. latipes and the partial cDNA sequence from $A$. charrua $(84 \%$ bootstrap support). The minor one is integrated by alternative splic- 


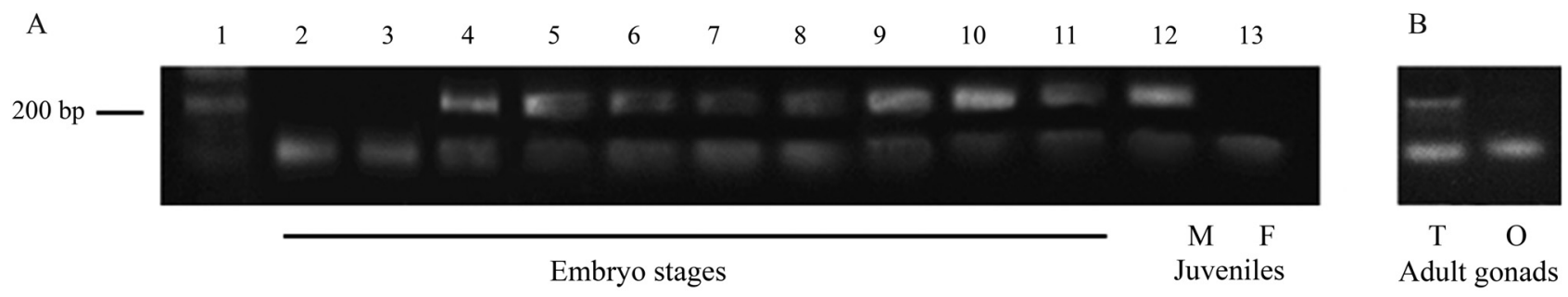

$\mathrm{C}$

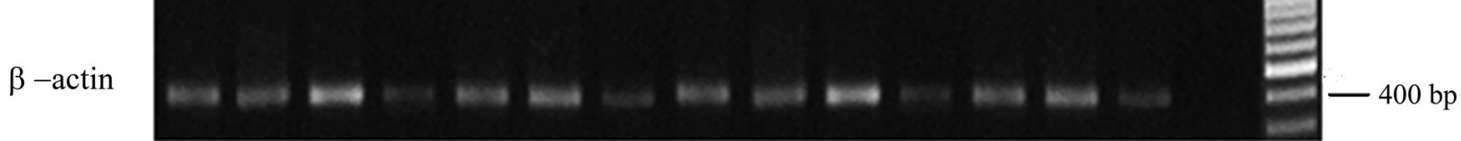

Figure 3 - Amplification products of candidate sex-specific gene expressed in A. charrua. A)1: Mass Ruler DNA ladder (Fermentas); Embryo stages: 2:1-128 cells; 3: early blastula; 4: dispersion phase (annual fish late blastula); 5: reaggregation (annual fish gastrula); 6: 0 to 10 somites; 7: 10 to 20 somites; 8: 20 to 30 somites; 9: 3 weeks post fertilization; 10: 1 month post fertilization; 11: pre-hatching embryo; 12: M: male juvenile; 13: F: female juvenile. B) Adult gonads: T: testis, O: ovary. C) RT-PCR of the same embryonic, juvenile and adult cDNAs using $\beta$-actin primers.

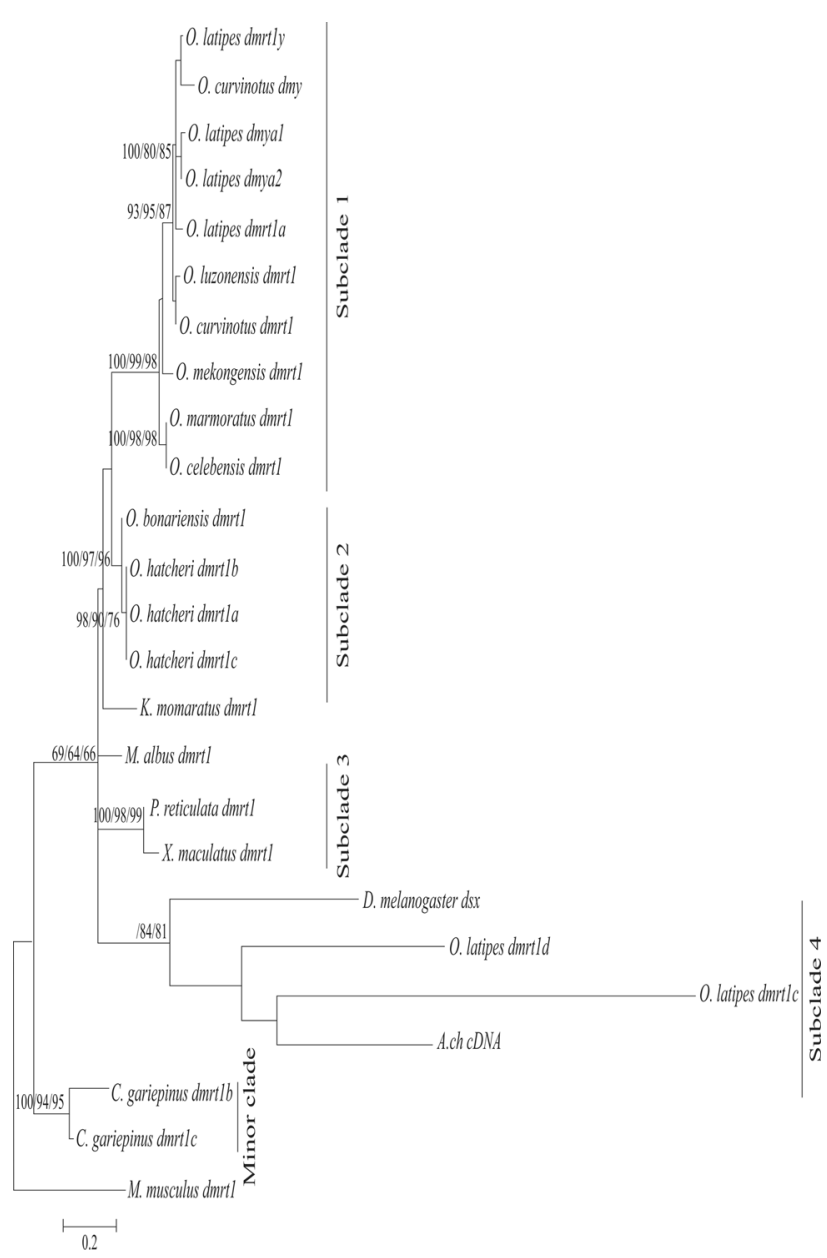

Figure 4 - Maximum Likelihood analyses [under $\mathrm{K} 81+\mathrm{G}$ model with gamma correction)], based on the expressed partial sex-specific cDNA sequence isolated from Austrolebias charrua (A.ch cDNA), Dmrt1/Dmrt1bY mRNA like sequences and $d s x$ from Drosophila retrieved from GenBank (Table 3). Numbers above the branches (left to right) correspond to the Bayesian posterior probability for clades obtained using BEAST $1.5 .4 \mathrm{v}$, followed by ML and MP boostrap support (> 60\%) respectively, recovered in 1000 replicates. ing versions of Dmrt1 from Clarias gariepinus (bootstrap support of 94\%). The mRNA Dmrt1 sequence from Mus musculus is the most divergent and not well supported basal taxon which collapsed in a basal polytomy with the remaining aforementioned clades.

All tree topology reconstruction methods revealed that the isolated partial cDNA sequence is more closely related to the small fragments amplified from male (M N1B) and female (H N2B) genomes (HPP > 96) and straightforward support the relationships of these sequences with the dsx D. melanogaster gene (HPP > 97) (Figure 5).

\section{Discussion}

Two fragments (M N1A and M N1B) were isolated from the $A$. charrua male genome. This pattern was similar to $O$. latipes male where a fragment of 1289 nucleotides corresponds to the Dmrtl gene and other of 965 nucleotides to the male specific duplicated gene version, Dmrt1bY (Nanda et al., 2002). It is worthy of notice that the same pattern was also found in the $A$. charrua female genome. Nucleotide sequence comparison of the larger fragments, $\mathrm{M}$ N1A and H N2A (1000 bp), showed 42\% similarity while the smaller fragments (900 bp), M N1B and H N2B are $99 \%$ similar. Thus, the smaller fragment is present in both sexes of the A. charrua genomes. In fish, five classes of Dmrt genes have been described: Dmrt 1, 2, 3, 4 and 5 (Huang et al., 2002). A moderate similarity was detected among the $A$. charrua genomic fragments and the Dmrt1 sequences. Therefore these results suggest a non conclusive relationship between the isolated fragments and the Dmrt1 from different fish groups.

The absence of a conserved DM domain in the partial cDNA fragment (205 bp) isolated in A. charrua males could be explained by restricted sequence information. The fragment length covers about the $11 \%$ of complete Dmrt $1 b Y$ and Dmrt 1 mRNAs reported in the GenBank. An- 


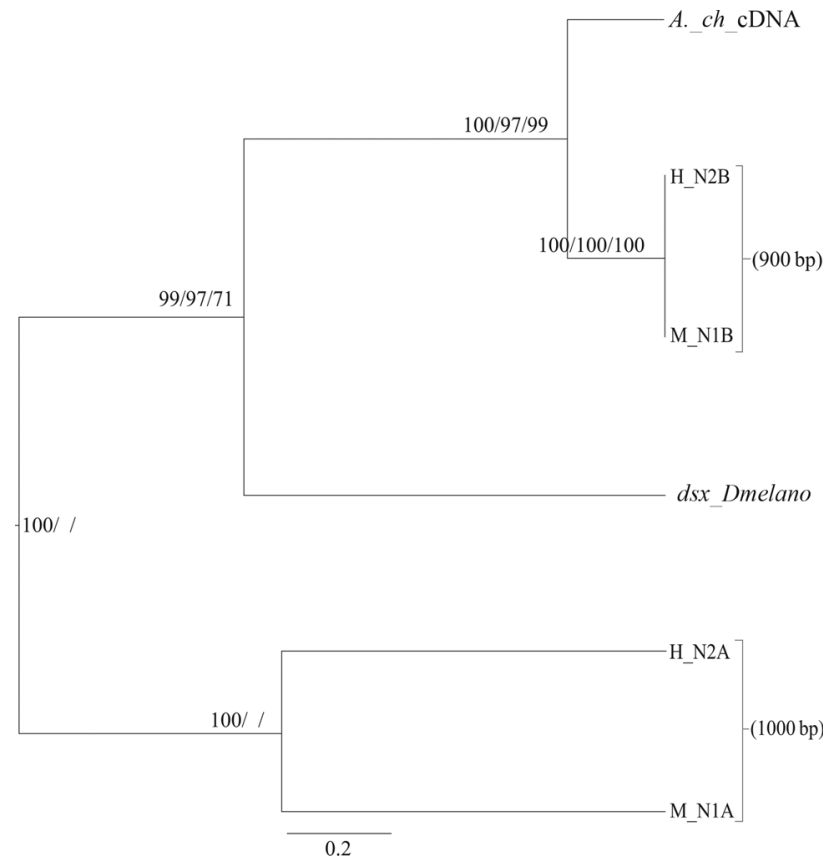

Figure 5 - Tree topology generated using the HKY 85 model of molecular evolution based on male (M N1A and MN1B) and female (H N2A and $\mathrm{H}$ $\mathrm{N} 2 \mathrm{~B}$ ) genomes, on the expressed partial sex-specific cDNA sequence isolated from Austrolebias charrua (A.ch cDNA) and the $d s x_{-} D$. melanogaster sequence. Bayesian phylogeographic inference framework implemented in BEAST 1.5.4v. Numbers above the branches (left to right) correspond to the Bayesian posterior probability for clades obtained using BEAST $1.5 .4 \mathrm{v}$, followed by ML and MP boostrap support (> 60\%) respectively, recovered in 1000 replicates.

other possibility could be that the DM domain is not present in the A. charrua fragment, as was shown for the Dmrtlc isoform from C. gariepinus and C. batrachus (Raghuveer and Senthilkumaran, 2009) and for the Dmrt1 gonadal isoform from mouse (Lu et al., 2007). Phylogenetic relationships among DM domain containing genes are not obvious in vertebrates, as different taxa show little sequence conservation outside this domain (Volff et al., 2003).

Phylogenetic analyses grouped the A. charrua expressed cDNA fragment with Dmrt1 alternative splicing versions c and d from $O$. latipes (Beloniformes) instead of Dmrt1 sequences from more closely related species of Cyprinodontiformes (K. marmoratus, $X$. maculatus and $P$. reticulata). This discordance may be explained by ancestral polymorphism maintenance or homoplasy. Evolution of homoplastic characters results from adaptations of different lineages in response to selective pressures in similar environments (Futuyma, 2005; Wake et al., 2011). Atheriniformes, Beloniformes and Cyprinodontiformes belong to the monophyletic Atherinomorpha Series. Beloniformes and Cyprinodontiformes are considered sister groups, while Atheriniformes occupies a basal position (Parenti, 2005; Nelson, 2006; Setiamarga et al., 2008). Thus, this discordance may be explained by ancestral polymorphism maintenance, as in the topology the A. charrua fragment grouped with $O$. latipes Dmrt $1 c$ and $d$ alternative splicing versions and Drosophila dsx. Furthermore, this clade is basally related with Odontesthes (Atheriniformes) Dmrt1 sequences. Discordance between Dmrt1 sequence relationships was also evidenced in phylogenetic analyses performed with Dmrtl from $O$. bonariensis (Atheriniformes) and other fish species (Fernandino et al., 2006).

Although homology relationships among members of the Dmrt family have not been clearly established in metazoans, it is interesting to consider that the Dmrtl gene is the closest related member in terms of structure and function to Drosophila dsx and Caenorhadbitis elegans mab-3 (Herpin and Schartl, 2011). In this sense, all phylogenetic analyses in the present work straightforward grouped Drosophila $d s x$ with $A$. charrua expressed cDNA partial fragment and amplified sequences from male (M N1B) and female ( $\mathrm{H}$ N2B) genomes showing high posterior probability of occurrence for such clade.

The expression pattern of cDNA partial sequence during the ontogeny of the studied species showed that this sequence is detected from dispersed phase (late blastula). This suggests that its expression depends on the zygotic genome activation (mid-blastula transition). Since no sex specific molecular markers are available to genotype the sex of the embryos, another possibility is that all the embryos analyzed at early stages ( 1 to 128 cells and early blastulas) were $100 \%$ females. In 1 to 128 cell embryos this probability is, however, only $0.004 \%$ and in early blastula stage it is $0.008 \%$. The probability of simultaneous occurrence of two or more independent events is calculated as the product of probabilities of each independent event (Canavos, 1988). We assumed the probability for a given embryo to be male or female to be 0.5 . For this reason, we consider that the absence of fragment amplification in these developmental stages indicates that it is not maternally supplied and that its expression depends on zygotic genome activation.

Oryzias latipes Dmrt1bY begins its expression during the neurula stage (1 day post fertilization), while Dmrt1a starts its expression during testis differentiation (about 20 days post hatching) (Iwamatsu, 2004; Nanda et al., 2002; Kobayashi et al., 2004). In A. charrua cDNA partial fragment expression was detected in an even earlier developmental stage than Dmrt1bY. This observation is in contrast to data documented from different vertebrate species. For instance, Dmrtl gene expression is identified later in ontogeny when a gonadal primordium is present (mouse, Raymond et al., 1999; turtles, Kettlewell et al., 2000; chicken, Smith et al., 2003). In most fish species analyzed, Dmrt1 gene expression was reported in post hatching stages $(C$. gariepinus, Raghuveer et al., 2011; Oreochromis niloticus, Ijiri et al., 2008; Sparus auratus, Liarte et al., 2007; Gobiocypris rarus, Zhang et al., 2008; Epinephelus coloides, He et al., 2003; M. albus, Huang et al., 2005; O. bonariensis, Strüssman et al., 1996; T. rubripes, Yamaguchi et al., 2006; Squalius alburnoides, Pala et al., 2009, Oncorhynchus 
mykiss Marchand et al., 2000; K. marmoratus, Kanamori et al., 2006; Halichoeres tenuispinis, Jeong et al., 2009). In D. rerio and Gadus morhua Dmrt1 expression was detected in pre-hatching stages. However, these embryos are in somitogenesis (Schulz et al., 2007; Johnsen and Andersen, 2012). Therefore, the finding that this cDNA partial sequence is expressed very early during $A$. charrua development and its closely phylogenetic relationships with the dsx_D. melanogaster gene, could be indicative that this sequence could play an essential role during the sex determination process and might be located near the top of the sex determination cascade in this species.

Taken together, these results suggest that both isolated A. charrua genomic sequences and the expressed cDNA partial sequence are more closely related to $d s x$ from D. melanogaster than the two alternative splicing Dmrt1sequences from O.latipes. The observed male-specific expression pattern supports the hypothesis that this sequence probably belongs to an alternative splicing Dmrt 1 gene version in A. charrua, as this gene is present in both sexes and represents the most conserved downstream gene member implicated in male sex development during vertebrate evolution. Nevertheless, it is also possible that the isolated cDNA sequence belongs to a class of abundant non-coding RNAs with potential regulatory function. Regulatory RNAs from 100 to 100,000 nucleotides are referred to as long non-coding RNAs (lncRNAs) because they have typical structures. It has furthermore been documented that splicing isoforms encode a protein, whereas other specific splicing isoforms encode regulatory lncRNAs that show tissue specificity and dynamic expression during development (Amaral et al., 2008, 2011).

The results obtained with RNAfold analysis (Gruber et al., 2008; Lorenz et al., 2011) evidenced that the $205 \mathrm{bp}$ cDNA sequence is capable of generating a stable secondary structure $\left(-84.39 \mathrm{Kcal} / \mathrm{mol}\right.$ at $\left.20^{\circ} \mathrm{C}\right)$ (Figure 6). This predicted secondary structure could be formed by lncRNAs, as mRNAs are usually not structured. Nevertheless, it is essential to obtain more sequence information (e.g. stagespecific transcriptomes) to elucidate $A$. charrua expressed cDNA sequence identity. To further evaluate if this RNA is effectively translated (characterization of expression pattern in temporal and spatial scales) the generation of specific antibodies would be necessary.

For sex determination studies in a given species it is important to consider the criterion proposed by Valenzuela et al. (2003) which emphasizes the presence of sex chromosomes as strong evidence for genetic sex determination (GSD). Sex chromosomes were, however, not identified in A. charrua (García, 2006), in agreement with data obtained from most studied teleosts. Cytogenetically differentiated sex chromosomes are sporadic in different fish taxa, suggesting a recent and polyphyletic origin of sex chromosomes in this vertebrate group (Mank et al., 2006). Fish sex chromosomes are difficult to evidence by classic cytogenetic techniques due to their putative recent origin (ho-
A

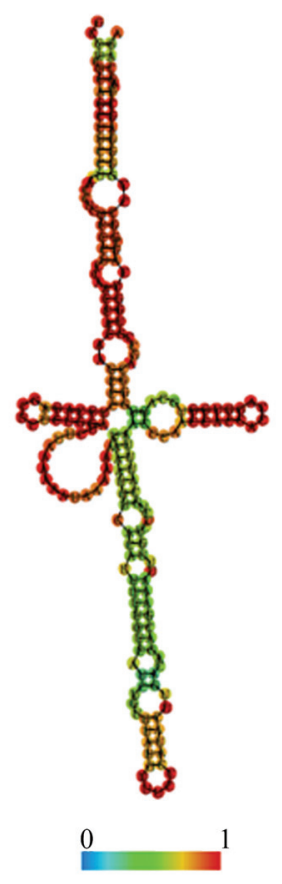

B

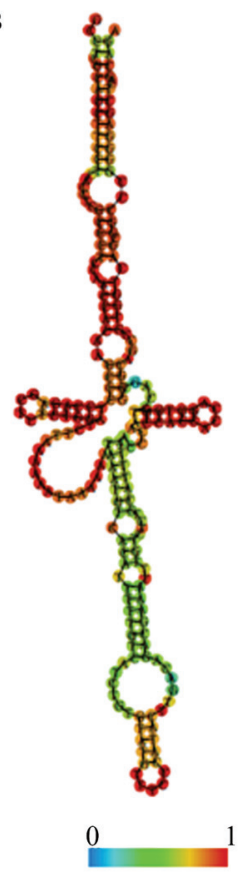

$\mathrm{C}$

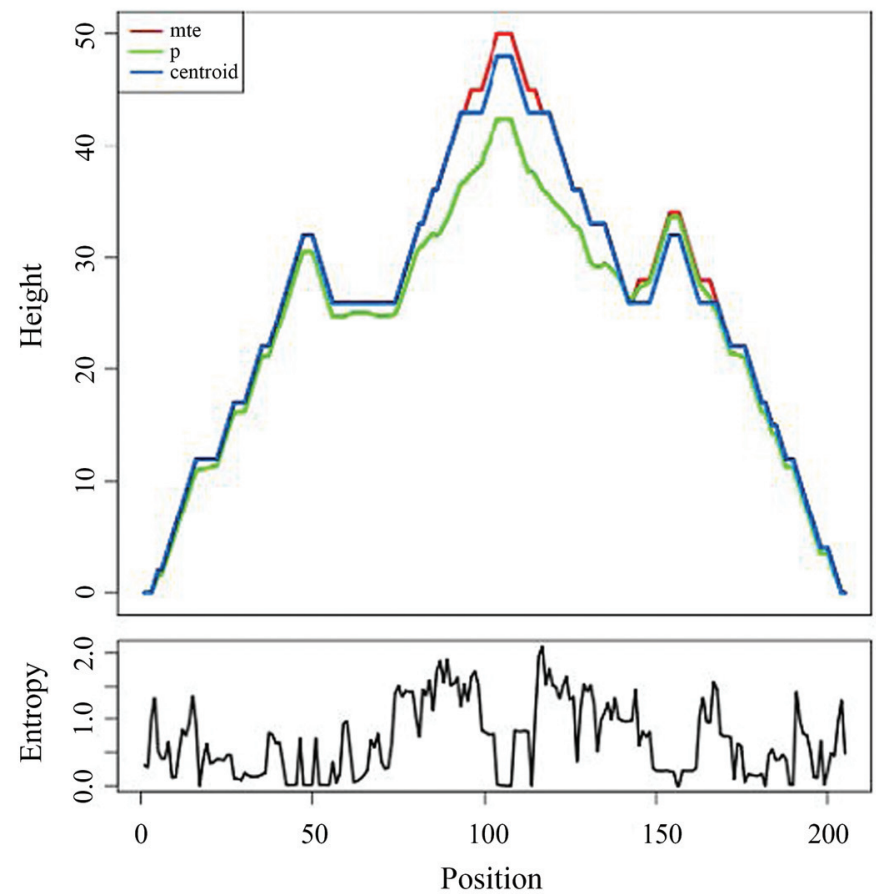

Figure 6 - RNA structure analysis obtained with RNAfold. A) Minimum free energy predicted structure (-84.39 Kcal/mol). B) Centroid secondary structure. In both images color intensity denotes base-pairing probabilities. For unpaired regions color is related to the probability of being unpaired. C) Mountain plot of minimum free energy structure, the thermodynamic ensemble of RNA, centroid structures and entropy for each position. 
momorphic chromosomes). Ultrastructural analyses of synaptonemic complexes could reveal tiny unpaired regions allowing sex chromosome pair recognition in the heterogametic sex (Devlin and Nagahama, 2002). This approach made it possible to identify sex chromosomes in $O$. niloticus (Carrasco et al., 1999). For this reason we cannot discard the presence of homomorphic sex chromosomes in A. charrua. Even in the absence of sex chromosomes, GSD may be demonstrated by the construction of a microsatellite-based linkage map to define genome regions involved in sex determination. This approach allowed the identification of the male sex determining non-recombinant region in the African annual fish Nothobranchius furzeri (Valenzano et al., 2009), similar to those identified in other phylogenetically related fish species as O. latipes (Matsuda et al., 2002; Nanda et al., 2002), Gasterosteus aculeatus (Peichel et al., 2004), X. maculatus (Schultheis et al., 2009) and $P$. reticulata (Tripathi et al., 2009).

\section{Acknowledgments}

The authors wish to thank Cora Chalar for her key assistance in technical approaches (RNA isolation and RTPCR), Nuria Lahuerta for her important help in setting up the molecular techniques, Leticia Pérez and Pablo Smircich for their helpful assistance with RNAfold results. We are very grateful for suggestions and improvements made by reviewers of this manuscript. The original findings presented in this paper were part of a PEDECIBA (Programa de Desarrollo Ciencias Básicas) PhD Thesis by MJ Arezo. Financial support was provided by Agencia Nacional de Investigación e Innovación (ANII FCE2007), Programa de Desarrollo de las Ciencias Básicas (PEDECIBA) and Facultad de Ciencias - Universidad de la República, Montevideo, Uruguay.

\section{References}

Akaike H (1974) A new look at the statistical model identification. IEEE Transact Autom Control AC 19:716-23.

Altschul SF, Gish W, Miller W, Myers EW and Lipman DJ (1990) Basic Local Alignment Search Tool. J Mol Biol 215:403410.

Amaral PP and Mattick JS (2008) Noncoding RNA in development. Mamm Genome 19:454-492.

Amaral PP, Michael BC, Dennis KG, Marcel ED and John SM (2011) lncRNAdb, a reference database for long noncoding RNAs. Nucleic Acids Res 39:D146-D151.

Arezo MJ, Pereiro L and Berois N (2005) Early development in the annual fish Cynolebias viarius (Cyprinodontiformes, Rivulidae). J Fish Biol 66:1357-1370.

Arezo MJ, D'Alessandro S, Papa N, de Sà R and Berois N (2007) Sex differentiation pattern in the annual fish Austrolebias charrua (Cyprinodontiformes, Rivulidae). Tissue Cell 39:89-98.

Barrallo A, Gonzalez-Sarmiento R, Garcia-Isidoro M, Cidad P, Porteros A and Rodriguez RE (1999) Differential brain ex- pression of a new beta-actin gene from zebrafish (D. rerio). Eur J Neurosci 11:369-372.

Berois N, Arezo MJ, Papa N and Clivio G (2012) Annual fish: Developmental adaptations for an extreme environment. WIREs Dev Biol 1:595-602.

Canavos G (1988) Probabilidad y Estadística. Método y Aplicaciones. McGraw Hill, Mexico, 667 pp.

Carrasco LAP, Penman DJ and Bromage N (1999) Evidence for the presence of sex chromosomes in the Nile tilapia (Oreochromis niloticus) from synaptonemal complex analysis of XX, XY and YY genotypes. Aquaculture 173:207218.

Conover DO and Kynard BE (1981) Environmental sex determination: Interaction of temperature and genotype in a fish. Science 213:577-579.

Costa WJEM and Cheffe MM (2001) Three new annual fishes of the genus Austrolebias from the Laguna dos patos system, southern Brazil, and a rediscription of $A$. adloffi (AHL) (Cyprinodontiformes, Rivulidae). Comun Mus Ciênc Tecnol PUCRS, Sér Zool, Porto Alegre 14:179-200.

Devlin RH and Nagahama Y (2002) Sex determination and sex differentiation in fish: An overview of genetic, physiological and environmental influences. Aquaculture 208:191364.

Drummond AJ and Rambaut A (2007) BEAST: Bayesian evolutionary analysis by sampling trees. BMC Evol Biol 7:e214.

Fernandino JI, Guilgur LG and Somoza GM (2006) Dmrt1 expression analysis during spermatogenesis in pejerrey, Odontesthes bonariensis. Fish Physiol Biochem 32:231240.

Fernandino JI, Hattori RS, Shinoda T, Kimura H, Strobl-Mazzulla PH, Strussmann CA and Somoza GM (2008) Dimorphic expression of Dmrtl and cyp19al (ovarian aromatase) during early gonadal development in pejerrey, Odontesthes bonariensis. Sex Dev 2:316-324.

Futuyma DJ (2005) Evolution. Sinauer Associates, Sunderland, $603 \mathrm{pp}$.

García G (2006) Multiple simultaneous speciation in killifishes of the Cynolebias adloffi species complex (Cyprinodontiformes, Rivulidae) from phylogeography and chromosome data. J Zool Syst Evol Res 44:75-87.

García G, Loureiro M, Berois N, Arezo MJ, Casanova G, Clivio G and Olivera A (2009) Pattern of differentiation in the annual killifish genus Austrolebias (Cyprinodontiformes, Rivulidae) from a Biosphere reserve site in South America: A multidisciplinary approach. Biol J Linn Soc 98:620-635.

Graves JA and Peichel C (2010) Are homologies in vertebrate sex determination due to shared ancestry or to limited options? Genome Biol 11:205.

Gruber AR, Lorenz R, Bernhart SH, Neuböck R and Hofacker IL (2008) The Vienna RNA Websuite. Nucleic Acids Res 36:W70-W74.

Guindon S, Dufayard JF, Lefort V, Anisimova M, Hordijk W and Gascuel O (2010) New algorithms and methods to estimate maximum-likelihood phylogenies: Assessing the performance of PhyML 3.0. Syst Biol 59:307-21.

Hasegawa M, Kishino K and Yano T (1985) Dating the human-ape splitting by a molecular clock of mitochondrial DNA. J Mol Evol 22:160-174.

He CL, Du JL, Wu GC, Lee YH, Sun LT and Chang CF (2003) Differential Dmrt1 transcripts in gonads of the protandrous 
black porgy, Acanthopagrus schlegeli. Cytogenet Genome Res 101:309-313.

Herpin A, Rohr S, Riedel D, Kluever N, Raz E and Schartl M (2007) Specification of primordial germ cells in medaka (Oryzias latipes). BMC Dev Biol 7:e3.

Herpin A, Braasch I, Kraeussling M, Schmidt C, Thoma EC, Nakamura S, Tanaka M and Schartl M (2010) Transcriptional rewiring of the sex determining Dmrt1 gene duplicate by transposable elements. Plos Genetics 6:e100844.

Herpin A and Schartl M (2011) Dmrt1 genes at the crossroads: A widespread and central class of sexual development factors in fish. FEBS J 278:1010-1019.

Hodgkin J (2002) The remarkable ubiquity of DM domain factors as regulators of sexual phenotype: Ancestry or aptitude? Genes Dev 16:2322-2326.

Hornung U, Herpin A and Schartl M (2007) Expression of the male determining gene Dmrt $1 \mathrm{bY}$ and its autosomal coorthologue Dmrt1a in medaka. Sex Dev 1:197-206.

Huang X, Cheng H, Guo Y, Liu L, Gui J and Zhou R (2002) A conserved family of doublesex-related genes from fish. J Exp Zool 294:63-67.

Huang X, Guo Y, Shui Y, Gao S, Yu H, Cheng H and Zhou R (2005) Multiple alternative splicing and differential expression of Dmrt1 during gonad transformation of the rice field eel. Biol Reprod 73:1017-1024.

Ijiri S, Kaneko H, Kobayashi T, Wang DS, Sakai F, Paul Prasanth B, Nakamura M and Nagahama Y (2008) Sexual dimorphic expression of genes in gonads during early differentiation of a teleost fish, the Nile tilapia Oreochromis niloticus. Biol Reprod 78:333-341.

Iwamatsu T (2004) Stages of normal development in the medaka Oryzias latipes. Zool Sci 11:825-839.

Jeong HB, Park JG, Park YJ, Takemura A, Hur SP, Lee YD and Kim SJ (2009) Isolation and characterization of Dmrt1 and its putative regulatory region in the protogynous wrasse, Halichoeres tenuispinis. Gene 438:8-16.

Jonhnsen H and Andersen Ø (2012) Sex dimorphic expression of five Dmrt genes identified in the Atlantic cod genome. The fish-specific Dmrt $2 b$ diverged from Dmrt2a before the fish whole-genome duplication. Gene 505:221-232.

Kanamori A, Yamamura A, Koshiba S, Lee JS, Orlando EF and Hori H (2006) Methyltestosterone efficiently induces male development in the self-fertilizing hermaphrodite fish, Kryptolebias marmoratus. Genesis 44:495-503.

Kettlewell JR, Raymond CS and Zarkower D (2000) Temperature dependent expression of turtle Dmrt1 prior to sexual differentiation. Genesis 26:174-178.

Kikuchi K and Hamaguchi S (2013) Novel sex-determining genes in fish and sex chromosome evolution. Dev Dyn 242:339353.

Kimura M (1981) Estimation of evolutionary distances between homologous nucleotide sequences. Proc Natl Acad Sci USA 78:454-458.

Kobayashi T, Matsuda M, Kajiura-Kobayashi H, Suzuki A, Saito N, Nakamoto M, Shibata N and Nagahama Y (2004) Two DM domain genes, dmy and Dmrt1, involved in testicular differentiation and development in the medaka, Oryzias latipes. Dev Dyn 231:518-526.

Kopp A (2012) Dmrt genes in the development and evolution of sexual dimorphism. Trends Genet 28:175-184.
Liarte S, Chaves-Pozo E, Garcia-Alcazar A, Mulero V, Meseguer J and Garcia-Ayala A (2007) Testicular involution prior to sex change in gilthead seabream is characterized by a decrease in Dmrt1 gene expression and by massive leukocyte infiltration. Reprod Biol Endocrinol 5:20.

Lorenz R, Bernhart SH, Höner Zu, Siederdissen C, Tafer H, Flamm C, Stadler PF and Hofacker IL (2011) ViennaRNA Package 2.0. Algorithms Mol Biol 6:e26.

Lu H, Huang X, Zhang L, Guo Y, Cheng H and Zhou R (2007) Multiple alternative splicing of mouse Dmrtl during gonadal differentiation. Biochem Biophys Res Commun 352:630-634.

Mank JE, Promislow DEL and Avise JC (2006) Evolution of alternative sex-determining mechanisms in teleost fishes. Biol J Linn Soc 87:83-93.

Marchand O, Govoroun M, D'Cotta H, McMeel O, Lareyre J, Bernot A, Laudet V and Guiguen Y (2000) Dmrt1 expression during gonadal differentiation and spermatogenesis in the rainbow trout, Oncorhynchus mykiss. Biochim Biophys Acta 1493:180-187.

Marin I and Baker BS (1998) The evolutionary dynamics of sex determination. Science 281:1990-1994.

Matsuda MY, Nagahama A, Shinomiya T and Sato C (2002) Dmy is a $\mathrm{Y}$-specific DM-domain gene required for male development in the medaka fish. Nature 417:559-563.

Medrano JF, Aasen E and Sharrow L (1990) DNA extraction from nucleated red blood cells. BioTechniques 8:43.

Myers GS (1952) Annual fishes. Aquarium J 23:125-141.

Nanda I, Kondo M, Hornung U, Asakawa S, Winkler C, Shan Z, Haaf T, Shimizu N, Shima A, Schmid M, et al. (2002) A duplicated copy of Dmrt1 in the sex determining region of the Y chromosome of the medaka, Oryzias latipes. Proc Natl Acad Sci USA 99:11778-11783.

Nelson JS (2006) Fishes of the World. $4^{\text {th }}$ edition. Wiley, Hoboken, $601 \mathrm{pp}$.

Pala I, Schartl M, Thorsteinsdóttir S and Coehlo M (2009) Sex determination in the Squalius alburnoides complex: An initial characterization of sex cascade elements in the context of a hybrid polyploid genome. PLoS One 4:e6401.

Parenti LR (2005) The phylogeny of atherinomorphs: Evolution of a novel fish reproductive system. In: Uribe MC and Grier HJ (eds) Viviparous Fishes. New Life Publications, Homestead, pp 13-30.

Peichel CL, Ross JA, Matson CK, Dickson M, Grimwood J, Schmutz J, Myers RM, Mori S, Schluter D and Kingsley DM (2004) The master sex-determination locus in threespine sticklebacks is on a nascent $\mathrm{Y}$ chromosome. Curr Biol 14:1416-1424.

Posada D and Crandall K A (1998) MODELTEST: Testing the model of DNA substitution. Bioinformatics 14:817-818.

Raghuveer K and Senthilkumaran B (2009) Identification of multiple Dmrtls in catfish: Localization, dimorphic expression patter, changes during testicular cycle and after methyltestosterones treatment. J Mol Endocrinol 42:437-448.

Raghuveer K, Senthilkumaran B, Sudhakumari CC, Sridevi P, Rajakumar A, Singh R, Murugananthkumar R and Majumdar KC (2011) Dimorphic expression of various transcription factor and steroidogenic enzyme genes during gonadal ontogeny in the air-breathing catfish, Clarias gariepinus. Sex Dev 5:213-223. 
Raymond CS, Kettlewell JR, Hirsch B, Bardwell VJ and Zarkower D (1999) Expression of Dmrt1 in the genital ridge of mouse and chicken embryos suggests a role in vertebrate sexual development. Dev Biol 215:208-220.

Rodríguez F, Oliver JL, Marín A and Medina JR (1990) The general stochastic model of nucleotide substitution. J Theor Biol 142:482-501

Sambrook J, Fritsch EF and Maniatis T (1989) Molecular Cloning. A Laboratory Manual. 2nd edition. Cold Spring Harbor Laboratory Press, NY, 1659 pp.

Schultheis C, Böhne A, Schartl M, Volff JN and Galiana-Arnoux D (2009) Sex determination diversity and sex chromosome evolution in poeciliid fish. Sex Dev 3:68-77.

Schulz RW, Bogerd J, Male R, Ball J, Fenske M, Olsen LC and Tyler CR (2007) Estrogen-induced alterations in amh and Dmrt1 expression signal for disruption in male sexual development in the zebrafish. Environ Sci Technol 41:6305-6310.

Setiamarga DHE, Miya M, Yamanoue Y, Mabuchi K, Satoh TP, Inoue JG and Nishida M (2008) Interrelationships of Atherinomorpha (medakas, flyingfishes, killifishes, silversides, and their relatives): The first evidence based on whole mitogenome sequences. Mol Phylogenet Evol 49:598-605.

Smith CA, McClive PJ, Western PS, Reed KJ and Sinclair AH (1999) Conservation of a sex-determining gene. Nature 402:601-602.

Smith CA, Katz M and Sinclair AH (2003) Dmrt1 is upregulated in the gonads during female-to-male sex reversal in $\mathrm{ZW}$ chicken embryos. Biol Reprod 68:560-570.

Strüssmann CA, Takashima F and Toda K (1996) Sex differentiation and hormonal feminisation in pejerrey Odontesthes bonariensis. Aquaculture 139:31-45.

Swofford DL (2002) PAUP*. Phylogenetic Analysis Using Parsimony (*and Other Methods). Version 4. Sinauer, Sunderland, $123 \mathrm{pp}$.

Tamura K, Dudley J, Nei M and Kumar S (2007) MEGA4: Molecular Evolutionary Genetics Analysis (MEGA) Software Version 4.0. Mol Biol Evol 24:1596-1599.

Tripathi N, Hoffmann M, Weigel D and Dreyer C (2009) Linkage analysis reveals the independent origin of Poeciliid sex chromosomes and a case of atypical sex inheritance in the guppy (Poecilia reticulata). Genetics 182:365-374.

Thompson JD, Gibson TJ, Plewniak F, Jeanmougin F and Higgins DG (1997) The CLUSTAL_X windows interface: Flexible strategies for multiple sequence alignment aided by quality analysis tools. Nucleic Acids Res 25:4876-4882.

Valenzano DR, Kirschner J, Kamber R, Zhang E, Weber D, Cellerino A, Englert C, Platzer M, Reichwald K and Brunet
A (2009) Mapping loci associated with tail color and sex determination in the short-lived fish Nothobranchius furzeri. Genetics 183:1385-1395.

Valenzuela N, Adams DC and Janzen FJ (2003) Pattern does not equal process: Exactly when is sex environmentally determined? Am Nat 161:676-683.

Volff JN, Zarkower D, Bardwell J and Schartl M (2003) Evolutionary dynamics of the DM domain gene family in metazoans. J Mol Evol 57:S241-S249.

Volff JN, Nanda I, Schmid M and Schartl M (2007) Governing sex determination in fish: Regulatory putsches and ephemeral dictators. Sex Dev 1:85-99.

Wake DV, Wake MH and Specht CD (2011) Homoplasy: From detecting pattern to determining process and mechanism of evolution. Science 331:1032-1035.

Wourms JP (1967) Annual fishes. In: Wilt FH and Wessels N (eds) Methods in Developmental Biology. Thomas and Crowell Company, New York, pp 123- 137.

Yamaguchi A, Lee KH, Fujimoto H, Kadomura K, Yasumoto S and Matsuyama M (2006) Expression of the Dmrt gene and its roles in early gonadal development of the Japanese pufferfish T. rubripes. Comp Biochem Physiol D 1:59-68.

Zhang X, Zha J and Wang Z (2008) Influences of 4-nonylphenol on doublesex- and mab-3-related transcription factor 1 gene expression and vitellogenin mRNA induction of adult rare minnow (Gobiocypris rarus). Environ Toxicol Chem 27:196-205.

\section{Internet Resources}

National Center for Biotechnology Information (NCBI) database, http:/www.ncbi.nlm.nih.gov/ (July 23, 2012).

New Algorithms and Methods to Estimate Maximum-Likelihood Phylogenies: Assessing the Performance of PhyML 3.0, http://atgc.lirmm.fr/phyml (November, 2013).

Rambaut A and Drummond J (2009) 'Tracer v.1.5', http://beast.bio.ed.ac.uk/Tracer. (November, 2013).

RNAfold

WebServer, http://rna.tbi.univie.ac.at/cgi-bin/RNAfold.cgi (November, 2013).

Associate Editor: Marcelo Guerra

License information: This is an open-access article distributed under the terms of the Creative Commons Attribution License, which permits unrestricted use, distribution, and reproduction in any medium, provided the original work is properly cited. 